\title{
The Reports on the Protection and Inheritance of Laifeng Di LongDeng
}

\author{
Ding Xiang \\ Shanghai Maritime University \\ Shanghai, China \\ 448716587 @qq.com
}

\author{
Guo Zhenhua \\ Jishou University \\ Jishou, China \\ 316225603@qq.com
}

\section{Keywords: Di Longdeng; Laifeng; Protection; Inheritance}

\begin{abstract}
Due to the differences such as the geographical environment, national characteristics, material conditions, history and culture and so on, dragon-dancing performances present various sights and unique style of performance contents. Di LongDeng, which is popular in Ban Shajie Village, Da Yanban Village Jiusi Town Laifeng County, has a unique Image structure and rich aesthetic art, exquisite performing skill and rich local culture and art connotation, which is called folk art wonderful work in the history of dragon dancing in China, bearing the national essence of the traditional culture and playing a positive role in the process of cultural heritage and history development.
\end{abstract}

\section{The Origin of the Di Longdeng and the Unique Cultural Artistic Style and Connotation}

The Origin of Di Longdeng. Enshi tujia and miao autonomous prefecture of hubei province Is located on the border of hunan, hubei, sichuan and guizhou, whchi is a multi-ethnic settlements, inhabited by tujia, miao, dong and other 29 national, ethnic minorities, accounted for $52.6 \%$ of the population.Da Banyan Village and Ban Sajie Village and other tujia villages are located in the southwest of Hubei province, whose south lies in the west of Hunan province and the west lies in the east of Chongqing.Located in the wuling mountainous hinterland, beside the coast of Xinxia River, the branches of Youshui River. The custom of the Tujia villages are of primitive simplicity. The terrain is high and cold and kung fu is also popular here."Dragon lantern" has been around for thousands of years of history in our country. Due to the influence of such factors as the geographical environment, national culture characteristics, history and regional culture, different styles of $\mathrm{Di}$ Longdeng culture come into being. The different "dragons" which are made of different materials represent sports cultural characteristics of a nationality such as Cao Balong, Mie Long, BU Yishan Long, Ban Denglong and so on.According to the introduction from the state " Di Longdeng " master showman, inheritance people Deng Bin (87 years old) , The forms of "Di Longdeng performance from Ban Sajie Village in Laifeng County are very rich and have a unique style and profound cultural connotation, especially the masses put hope on the mascot of "dragon" and take them as the embodiment of natural objects, so as to conquer the nature, to live a life with good harvest, to live and work in peace and contentment.

Di Longdeng which is played in the folk deduced from folk tale which handed down from generation after generation. The population of the two villages, Ban Sajie and Da Yanban is no more than 3500. Because living in the high mountains, they have the custom of worshiping NUO and witchcraft. They have deep-rooted concept about dragon worshiping, phoenix worshiping and tiger worshiping. Di Longdeng performance is one of their main activities, and handed down from generation to generation. The two village people rejoice together with happy and live in harmony. They take "Di Longdeng" show as spirit consolation, so as to ward off evil spirits and exorcism, to pray for enjoying a happy, peaceful and long life.

Culture Art and Style. "Di Longdeng" performance is very entertaining and ornamental, especially, its performing props are delicate and quaint, colorful and beautiful, which not only has 
unique artistic quality of the dragon, but also has cultural forms including phoenix, tiger, shrimp, turtle, so as to form various cultural artistic value.Its style of acting and the line-up are very conspicuous, especially dragon players hide within the body of the dragon, not show the players' body with low walk step, fast and agile.The phrase says "Di Longdeng, Di Longdeng, no MieLou no sticks, walk like the dragon...." The action of "Di Longdeng" is extremely strong, with movements of a certain folk traditional martial arts, which have both multi-culture interest and have noble perfect entertainment. Its routines are interlocking, freaky, strange name, various forms, such as dragon flying out of the hole, dragon rolling on the beach, longpan cake, dragon mating, dragon teasing phoenix, dragon, robbing treasure, phoenix riding on a dragon's back, etc. Especially, at the end of the performance, music is loud and compact, the double phoenix are riding on the back of double dragons, wings stretch out and chirping, which means good fortune and happy, peaceful and long life. So, it is a culture and art treasures of tujia. Especially, at the end of the performance, music is loud and compact, the double phoenix are riding on the back of double dragons, wings stretch out and chirping, which means good fortune and happy, peaceful and long life. So, it is a culture and art treasures of tujia.

The Connotation. "Di Longdeng" performance depends on its own national belief consciousness, which is full of fantasy fiction. And the historical background of "Di Longdeng" performances has bizarre plot and touching story, which is very attractive to everyone. "Dragon" acts as the embodiment of nature. People are willing, with the aid of ancestors and the dragon's power, to overcome the bad nature, to escape the attacks from the evil beasts and prey insects, each other's kill and ruthless natural and man-made disaster, thus, people put all hope on the "dragon". Hope can bring them good luck. Since the will produced, it is just with a sacrifice of inspiration, one is to sacrifice with the corn, stencil candle, pigs, cattle and sheep; the other is to sacrifice in a way of entertainment. So it is: "Di Longdeng" performance is the origin of tujia's external objective conditions and internal noble.

\section{The Rise And Fall Of " Di Longdeng"Inheriting}

The Inheritance History Of "Di Longdeng" Experiencing. "Di Longdeng" performance includes the numerous custom culture, ethics, religious faith, has multi-element profound connotation. In principle, it holds its own national flavor, with the reality, and in accordance with the national idea, pass it down from generation after generation. In the process of inheritance, there have been several times in the situation of disappearance. According to Di Longdeng inheritance people Deng Bin: At the end of qing dynasty, the local people, who were on a way of "Di Longdeng" performance, were robbed by bandits and the beautiful actress playing phoenix was rent away, the leader of the light team, was killed, which made "Di Longdeng" performance have been in death for many years. By the middle of the republic of China, the revolutionary party Zhang Changqi led the local farmers and took advantage of Di Longdeng performance to promote revolutionary truth in Gao Dong village, Jiu $\mathrm{Si}$ village and San Hu Village, who had been harassed by local vigilante and local bao-jia system. "Di Longdeng" was said to act as a communist propaganda tool and was banned by the local national government, which made the folk culture had been disconnected for more than ten years. After the liberation, the local people under the organization of the communist party, put donwn the local tyrants, fought the landlord, shared the fields. The villagers of Ban Sajie village were jubilant and played up "Di Longdeng" again. In the 60s, suffered another cultural revolution, "Di Longdeng" performance was banned as "broken capitalism"."Di Longdeng" performance inheritance Deng Bin was put on the "bad guy" cap and was criticized and denounced at a public meeting, forced to leave home, wandering outside. Until 1980s, after the reform and opening up, Deng Bing returned his hometown. Through the "three people" integration work that the local cultural township and county cultural center organized, after the collection, sorting, digging a complete set of "Di Longdeng" performance information, "Di Longdeng" performances were restored, and repeatedly participate in the spring yuanxiao festival 
performance organized by county cultural departments. In the $1980 \mathrm{~s}$, province and state television stations sent "Di Longdeng" performance program to China central television station, broadcasted in the Spring Festival gala evening, and had a great influence at home and abroad. Many foreign news media came to Gao Dong Village and interviewed. "Di Longdeng", the traditional folk culture, won the great popularity. In 1993, "Di Longdeng" was invited to participate in national games opening ceremony performance of hubei province and won the first performance prize. In 1995 ,Taiwan's film crew "Eight thousand miles and clouds" came to organize "Di Longdeng" performance, and which was screened in full. By producing works of art, promoting the improvement in overseas, The influence of "Di Longdeng" performance is greater. Later, with the development of market economy, many entertainers joined DaGongChao, and "Di Longdeng" performance has been in the third endangered state. Until 2001, the original people of bureau to jun, during management bureau of the people of work, are very concerned about their own national "dragon lantern" performance, with the support of his, in the old division in township township organization seriously, "dragon lantern" performing this project and to regain a new life. It was not until 2001 that Di Longdeng show regain a new life. "Di Longdeng" representative inheritance person Deng Bin and Li Ying play a role of inheritance and instruction, which make a "Di Longdeng" show more endowed with tujia folk traditional performance characteristics. And many times, "Di Longdeng" was invited to the show by tourism festival in and out of provinces, garden party,arts festivals . In 2007, "Di Londeng" was invited to CCTV <Cui Yongyuan><the big Spring Festival Gala Show>, which made tujia " Di Longdeng" performance have a significant impact at home and abroad.

New Test the Protection and Inheritance of Di Longdeng Facing. "Di longdeng" has a unique value for the performing arts and artistic style and has their own national cultural deposits of tujia people. Therefore, in the representative report of the provincial and national intangible cultural inheritance, Di Lengdeng pasted the experts' evaluation for one time and successfully won the provincial and national intangible cultural inheritance list. Although the project has gained the highest value and also faced many new tests.

The first is that the government doesn't attaches great importance to Di Longdeng. As a provincial and national intangible cultural heritage, country attaches great importance to the protection and inheritance, and allocate funds on the heritage protection, but the government at all levels lacks experience how to protect the heritage.

The second is the development of market economy, a lot of old actor lost inheritance ability, young artists leave their villages for making money, which makes the professional actors of Di Longdeng performance considerabale reduction.

The third is that the cost of performance organized by the government is very expensive. According to the cost from Ji Si Town, who took part in e large hands waving festival activities held by county, which cost them props, costumes, delays subsidies, life vehicle expenses spent more than ten thousand yuan. To protect and inherit the folk arts like this, not only the local government, hut also the administrative villages and folk artists can't bear .

The fourth is the lack of overall planning for the protection and inheritance. The concept of the protection and inheritance is blur. Cultural propaganda department and performing artists at the grassroots level don't cooperate well. The concept of implementation, training of the policy related with the non-material cultural heritage is not clear.

\section{Suggestions for the Inheritance and Protection of Intangible Cultural "Di Longdeng"}

In recent years, with the development of government protecting intangible cultural heritage work, grass-roots culture gains new life again, which brings fresh air for non-material cultural heritage "Di Longdeng". In order to protect, inherit and carry forward the heritage arts and culture essence, acting as the cultural characteristic areas in the western minority, Enshi County is more rigorous for cultural inheritance and protection, who gives the economic support and legal policies support greatly. 
Sticking To Its Authenticity And Original Nature. "Di Longdeng" performance is not single, it has a variety of cultural and artistic connotation. We must adhere to its authenticity and original nature and carry out the inheritance and protection of Di Longdeng in accordance with its environment. Its authenticity include its concept, faith, props, routine action, forms, music, etc. which should be in accordance with the traditional essence to inherit. The props is mie with paper color coating, a treasure, a dragon, a phoenix, a tiger, a turtle, a mussel, a shrimp and so on. more or less will lost its its authenticity and original nature. Otherwise, it will lose the great significance of the non-material cultural heritage inheritance and protection.

Clarify The Concept Of Heritage Protection Theoretically. Local government take the lead and pay attention to the academic research of Di Longdeng, and explore its morphological characteristics, historical, social and cultural background, study its philosophy thoughts and aesthetics basis and cultural connotation. From the three levels, that is its concept, the idea, the behavior, to explore its artistic value and ethnic value, and introduce the results into primary and middle school classroom. let men and women, old and young in the local inheritance, love and enjoy the folk cultural treasures, which promote national feelings and sense of national pride.

To promote the protection and inharitance with overall planning. "Di Longdeng" show is a state-level non-material cultural heritage, protection and inheritance, in addition to realizing the value of the national culture, also need a certain amount of material means to support. Government departments at all levels should attach great importance to it and have the overall planning. On the basis of maintaining nationality and conforming to the times constantly promote the protection and inheritance. Must firmly seize the theme of the protection and inharitance.

To respect and create atmosphere, pay attention to human resources. To protect the cultural ecological village of "Di Longdeng", at the same time, improve the social status of "Di Longdeng" performing artists, especially, the older people with qualifications deepers, giving some living wage and honor. Governments on the state and county level should, according to the provincial and national policies about the heritage protection and inheritance, combined with the local reality, take effective measures to respect artists, and take the implement affordable.

To Raise Awareness of the Protection and Inheritance and Reach Consensus as soon as Possible. Local authorities take "Di Longdeng" performance, the intangible cultural heritage representative work, as a kind of unique folk art to build brand, especially some successful experience of intangible cultural heritage protection and inharitance at home and abroad for reference. Combining strong county for tourism with development policy of Wuling mountain area, absorb investment promotion and capital introduction, make the "Di Longdeng" acting as a unique national culture and art brand, let it be the highlight of their own national art brand, to truly protect the space of the protection and inheritance, which can improve their national cohesion, and popularity. At the same time, the inheritance and protection of 'Di Longdeng "performance should be included in the budget by local governments, to achieve the effective protection and inheritance.

Rich "dragon lantern" education inherited form of intangible cultural heritage. National traditional sports in China because the beliefs and folk sports itself has certain factions of clan and conservative, self belonging solid conventions people maintain the feeling of purity and spirit of the inheritance of the project, but on the other hand, for the inheritance of folk sports development and formed certain constraints. Therefore, increasing to dragon lantern of the intangible cultural heritage education tradition form, integration of the existing family dynasties patrimony, oral teaching of teacher and pupil, enlightening education, community organization and school performance activities such as all kinds of communication in the form of a game, from a different perspective to the sustainable development of the implementation to dragon lantern non-material cultural protection and carry forward.

National Culture Innovation Of "Di Longdeng" Non-material Cultural Heritage. The development and Innovation of "Di Longdeng" Non-material Cultural Heritage originates from life and spread in the folk. Its primitive simplicity style is in the development of the society and continues 
the new concept of culture in the development of the society. The characteristics of Di Longdeng 's entertainment and fitness should be incorporated into the the life of people feeling, The inheritance and changes of Di Longdeng upholed the fundamental spirit of the original ecological folk culture form, and abide by the regulation of folk culture development and vicissitude. The cultural innovation should mix the modern factors into Di Longdeng non-material culture, follow the principle of "ancient and modern combination". Go to its dregs, takes its essence. Protect local intangible cultural survival foundation. Raise the scientization socialization, industrialization level of Tujia nationality traditional sports. Strengthen the maintenance of Di Longdeng cultural ecological area, in order to ultimately ensure the continuation of Di Longdeng non-material cultural heritage. Only in this way can make Di Longdeng intangible cultural heritage have real life.

\section{Conclusion}

Di Longdeng at Ban Sajie Village, JiuSi Town, Laifeng County has been there for three hundred years. When on every Chinese New Year and May 15 " Dragon Boat Festival", Di Longdeng shows in every villages. The masses love it very much. In addition to the entertainment function, local people think it can sweep evils and pray for harvest year. Di Longdeng combines dragon, phoenix, tiger together, has a profound cultural connotation, widespread mass base. Laifeng Di

\section{Acknowledgment}

Social science fund project of hunan province (15 YBA318); Scientific research key project of hunan province department of education (15A154); Open-end fund project of national sports key research base of State general sports administration (14jdzb023).

\section{Reference}

[1] Xu Xiaoqin, A Research on the evolvement and development of Hunan folk dragon dance-in the view of intangible culture heritage, Hunan Formal University, 2009,79-81.

[2] Peng Jingshan, Thinking of the Implementation of the Project of the Protection of Non-matter Cultural Inheritance, The northwest ethnic studies, 2006(1):147-150.

[3] Long Xianqiong, Connotation and Characters of Intangible Cultural Heritage and Protection,Journal of hubei institute for nationalities (philosophy and social sciences edition), 2006(5):48-50.

[4] Xu Xiaoqin,Lei Junrong,Zhang Jisheng,Inheritance Model on Village Folk Sports as Intangible Culture, Heritage based upon the study of fiery dragons of Rucheng, Chenzhou of China. Martial arts (wushu science), 2010(12):97.

[5] Qing Qing, The present situation of the abroad to protect intangible cultural heritage.Journal of observation and thinking,2007(14):62-63.

[6] Origin, present situation and related problems of the concept of intangible cultural heritage. Journal of the world of cultural relics,2003(02):27-28.

[7] SHI Jiguang, YU Xuecai, A Summary of Research on Intangible Heritage in Recent Years.Journal of changsha university ,2006(01):10-11.

[8] Many experts point out that the intangible cultural heritage protection needs more theoretical support[N]. Chinese Arts Newspaper,2008.01,04.

[9] Qin Mingzhu, Village folk sports to LongDeng inheritance and the protection mechanism. Hunan University, 2012:18-24. 
[10] Tan Zhiguo, On the Conservation and Exploitation of Intangible Cultural Heritage of Tujia Ethnics. South-Central University for Nationalities, 2011. 